\title{
Craniovertebral junction tuberculosis
}

\author{
Naveen Kumar, Adesh Kumar Gadpayle, Deepak Sundriyal, Deepshikha Trisal
}

Department of Medicine, PGIMER, Dr RML Hospital, New Delhi, India

\section{Correspondence to}

Dr Naveen Kumar, docnaveen2605@yahoo.co.in

\section{DESCRIPTION}

A 26-year-old woman presented with occipital and upper neck pain, left upper limb weakness and a lump on the left side of the neck for 3 months, followed by weakness in the other three limbs for last 1 month. She was bedridden for 15 days prior to admission. On examination, she had left-sided torticollis: left-sided, multiple, matted cervical and axillary lymphadenopathy. A fluctuant swelling of size $4 \times 3 \mathrm{~cm}$ was present in the left upper part of the neck. Neurological examination revealed leftsided lower motor neuron type of 12th cranial nerve palsy, asymmetric spastic quadriparesis more marked on the left, hyper-reflexia, bilateral Babinski's signs, hypoesthesia below C3 dermatome. Higher mental functions, the rest of cranial nerves and cerebellar function were normal, as was examination of other systems. MRI of the cervical spine showed: destruction of the anterior arch and lateral mass of the atlas, atlantoaxial and atlanto-occipital dislocation; erosion of odontoid

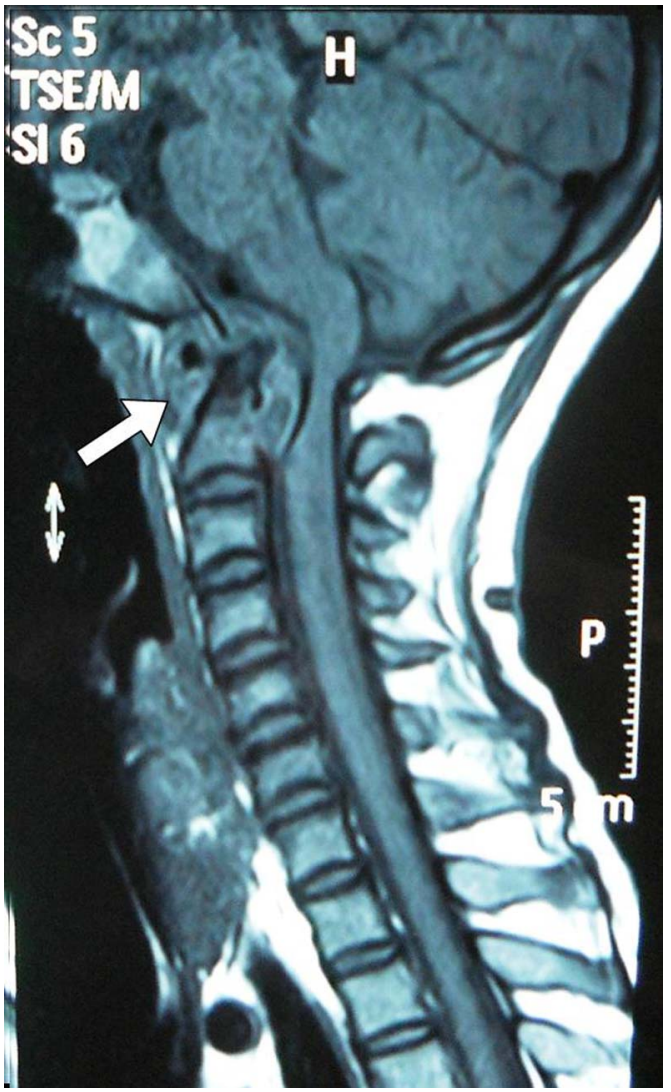

To cite: Kumar $\mathrm{N}$ Gadpayle AK, Sundriyal D, et al. BMJ Case Rep Published online: [please include Day Month Year] doi:10.1136/bcr-2013202136
CrossMark

Figure 1 Infective spondylitis of craniovertebral junction (white arrow): sagittal post-contrast T1-weighted image showing erosion of odontoid process with sclerosis and associated peripherally enhancing abscess leading to cervicomedullary compression and minimal cord oedema. Small eroded bony fragment seen in abscess. process with sclerosis; peripherally enhancing abscess leading to cervicomedullary compression and minimal cord oedema (figure 1). An abscess at the level of C 1-2 was continuous with the $4.3 \times 2.8 \mathrm{~cm}$ abscess in the left paraspinal region (figure 2). The aspirate from the cervical abscess was positive for acid fast bacilli. The patient was managed conservatively with immobilisation of the neck, antigravity aspiration of the cold abscess, intravenous steroids and antitubercular drugs. Third postadmission day, her power started improving, and by the end of 4 weeks, she was able to walk. Immobilisation of the neck was continued for 6 months, and the follow-up MRI showed resolution of the vertebral abscess. Tuberculosis of the upper cervical spine is extremely rare $(0.3-1 \%$ of vertebral tuberculosis). ${ }^{1}$ Differential diagnoses of craniovertebral junction tuberculosis are: pyogenic (brucellosis) infection, fungal infections, lymphoma, chordoma, metastases, primary bone tumours, sarcoidosis and rheumatoid arthritis. There is great variability in the management of this condition. Prolonged bed rest and skull traction has been reported to be successful even in advanced disease. ${ }^{2}$ Surgical intervention is indicated for progressive neurological deficit, lack of response to conservative treatment or when the diagnosis is in doubt especially when a neoplasm cannot be excluded. ${ }^{1}$

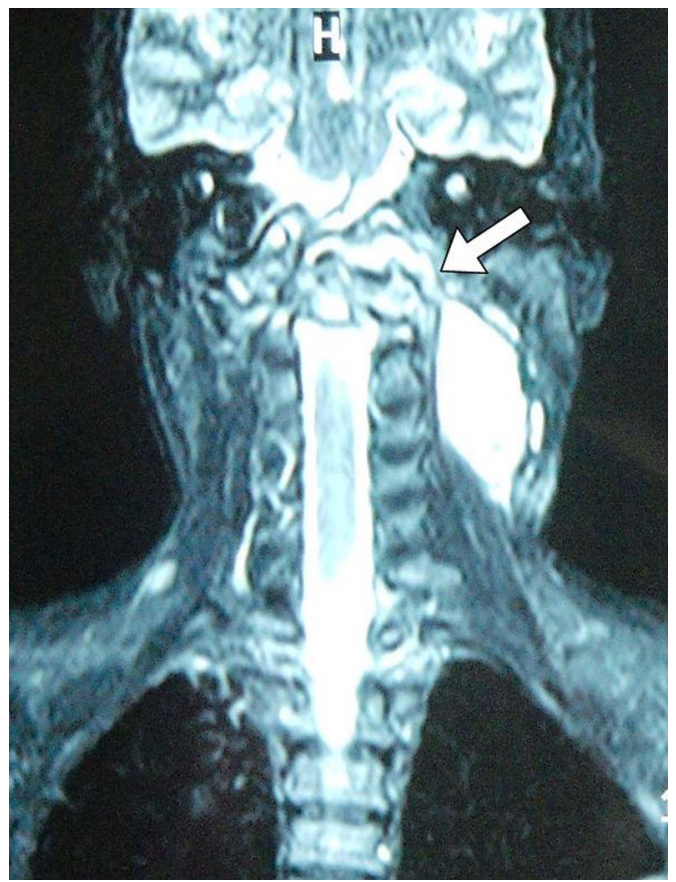

Figure 2 Coronal T2-weighted image shows the hyperintense cold abscess in periodontal region and extension in the left paraspinal/posterior triangle region (white arrow). 


\section{Learning points}

- Craniovertebral junction (CVJ) tuberculosis can have fatal consequences due to two reasons: proximity to neurovascular structures and unstable CVJ articulation.

- Conservative treatment is a viable initial approach, even in advanced disease.

- CVJ tuberculosis (TB) should be considered as an important differential diagnosis in patients with features of cervicomedullary compression, especially in area where TB is endemic.
Contributors NK was involved in diagnosis, management, conception of article, data acquisition, drafting article, revision of article and final approval. AKG was involved in diagnosis, management, conception of article, drafting article, revision of article and final approval. DS was involved in diagnosis, management, conception of article, drafting article, revision of article and final approval. DT was involved in diagnosis, management, data acquisition, drafting article and final approval.

Competing interests None.

Patient consent Obtained.

Provenance and peer review Not commissioned; externally peer reviewed.

\section{REFERENCES}

1 Behari S, Nayak SR, Bhargava V, et al. Craniocervical tuberculosis: protocol of surgical management. Neurosurgery 2003;52:72-80.

2 Gupta SK, Mohindra S, Sharma BS, et al. Tuberculosis of the craniovertebral junction: is surgery necessary? Neurosurgery 2006;58:1144-50.

Copyright 2013 BMJ Publishing Group. All rights reserved. For permission to reuse any of this content visit

http://group.bmj.com/group/rights-licensing/permissions.

BMJ Case Report Fellows may re-use this article for personal use and teaching without any further permission.

Become a Fellow of BMJ Case Reports today and you can:

- Submit as many cases as you like

- Enjoy fast sympathetic peer review and rapid publication of accepted articles

- Access all the published articles

- Re-use any of the published material for personal use and teaching without further permission

For information on Institutional Fellowships contact consortiasales@bmjgroup.com

Visit casereports.bmj.com for more articles like this and to become a Fellow 